\section{Saúde mental e}

\section{relações étnicas:}

\author{
formação do
}

\section{psicólogo para 0}

\author{
SUS e o SUAS,
}

\section{colonização e}

\section{currículo}

\author{
Regina Marques de Souza Oliveira \\ Universidade Federal do Recôncavo da \\ Bahia (UFRB) \\ marquesregina@uol.com.br \\ Joice Naiane Santos Lima \\ Universidade Federal do Recôncavo da \\ Bahia (UFRB) \\ joicenaiane19@hotmail.com
}

DOI: https://doi.org/10.22481/odeere.v0i4.2372
Resumo: 0 artigo aborda a saúde mental da população negra a partir da intersecção entre psicologia social, psicologia clinica psicanalítica e relações étnicas e raciais. A partir de literaturas clássicas sobre o tema, analise do currículo formativo e levantamento dos relatórios finais de estagio em psicologia de duas universidades do nordeste brasileiro apresentamos as analises parciais. Os resultados revelam que ainda há muito a fazer para que a ciência psicológica reconheça formalmente em seu currículo as demandas do sofrimento psíquico da população negra. Pois o assunto é marginalizado ou preterido por profissionais da saúde mental que atuam na universidade brasileira.

Palavras-Chave: psicologia, saúde mental, relações étnicas e currículo.

Abstract: The article addresses the mental health of the black population from the intersection between social psychology, psychoanalytic clinical psychology and ethnic and racial relations. Based on classical literature on the subject, analysis of the formative curriculum and the final report of internship in psychology of two universities in the Brazilian Northeast, we present the partial analyzes. The results reveal that much remains to be done to ensure that psychological science formally recognizes in its curriculum the demands of the psychic suffering of the black population. For the subject is marginalized or deprecated by mental health professionals who work in the Brazilian university. 
Keywords: psychology, mental health, ethnic relations and curriculum.

A psicologia brasileira é fruto da determinante influência das ideias psicológicas desenvolvidas na Europa, em Portugal, pelos jesuítas no período colonial.

Muitas das expressões e estudiosos da época, final do século XV, preocupavam-se em conhecer e desenvolver métodos de opressão e submissão das populações indígenas aos dominadores europeus. Dedicavam-se a pesquisar e escrever assuntos sobre técnicas de persuasão de selvagens como modo de manter seus domínios psíquicos e físicos sobre o corpo e a cartografia do território brasileiro.

O interesse dos europeus pela adaptação ao ambiente como tema da psicologia e a relação com a população indígena abordava a questão do "caráter brasileiro" Nesta consideração observamos o prenuncio da psicologia social no Brasil a partir de vários autores, como Padre Vieira e Mello Franco, que o comportamento é determinado também pelo clima tropical; sendo que este favorece o ócio e a dissimulação, privilegiando uma formação psicológica e moral inclinada para a ausência da luta e do trabalho em primazia da preguiça e da inatividade ${ }^{1}$.

A questão do território colonizado inscreve na psique humana do povo brasileiro - negro, indígena e branco - a formação de identidade e pertencimento étnico conforme as premissas ideológicas disseminadas por uma ciência psicológica em formação no mundo europeu e implantada no Brasil.

Estas relações étnicas entre brancos europeus, indígenas e negros, terão decorrências na epistemologia de todos os campos do conhecimento no território brasileiro. Mas é na psicologia que estas inaugurações se darão de modo emblemático a partir do arcadismo do ingresso do europeu no solo indígena na América dita portuguesa.

Este plano inaugural da psicologia no cenário brasileiro fomentara os currículos formativos desta ciência em nossa realidade. E estas formas de inscrições da psicologia estão presentes ainda hoje, no século XXI, nas disciplinas e componentes curriculares dos cursos de saúde e psicologia oferecidos nas universidades brasileiras.

Por tal razão a analise detida da formação curricular dos cursos de psicologia no Brasil deve ser objeto de pesquisas fundamentais para o aprimoramento da formação do profissional de saúde mental como é o caso do psicólogo.

\footnotetext{
${ }^{1}$ ANTUNES, Mitsuko Aparecida Makino. A psicologia no Brasil. Leirura historia sobre sua constituição. Educ/São Paulo, 2015, p.20.
} 
A psicologia como campo da saúde mental possui importantes marcos de consideração sobre o negro escravizado no Brasil. Principalmente a partir do pioneirismo da pesquisadora e psicanalista Virginia Bicudo. Ela foi uma brilhante intelectual, mulher e negra que protagonizou a difusão da psicanalise no Brasil juntamente com Durval Marcondes em São Paulo, fortalecendo a visibilidade dos estudos em psicologia, sociologia, politica e psicanalise no cenário paulista e nos eixos de grande efervescência cultural e intelectual do pais. Virginia além de formar a elite intelectual paulista, protagonizando estudos e difundindo seus conhecimentos nas universidades e escolas de formação superior em São Paulo, como a Escola de Sociologia e Politica, instituição clássica e importante de discussão e formação de pesquisadores em São Paulo, fundou a Associação de Psicanalise de Brasilia, que juntamente com São Paulo, local em que Virginia foi importante personalidade de desenvolvimento das atividades e direções que se realizavam na SBPS, articulou a visibilidade internacional da psicanalise brasileira através de sua inserção na Europa - Inglaterra - como psicanalista e estudiosa do comportamento e psique humana a partir da relação com os aportes sociais. As experiências na Inglaterra com psicanalistas como Melanie Klein e Bion, fizeram de Virginia uma das mulheres negras e profissionais da psicanalise, da psicologia e das ciências sociais, mais atuantes, brilhante e reconhecida nos espaços em que atuou, incluindo o contexto internacional europeu.

O protagonismo de Virginia Leone Bicudo na pesquisa sociológica e pesquisa do comportamento humano - psicanalise - foi emblemática e pioneira para o desenvolvimento de dois campos epistemológicos da ciência no Brasil: as ciências sociais e os estudos em relações étnicas e raciais e a psicologia a partir da década de 40 . Influenciando estudos e pesquisas sobre a sociedade brasileira e a psicologia, no caso a a formação da psicanalise e de psicanalistas no Brasil, até meados dos anos 90. Ou seja: mais de 50 anos de influência importante para os campos do conhecimento em psicologia, psicanalise e ciências sociais no Brasil e a interseccsionalidade étnica e racial.

Em 1995, Virginia Bicudo escreve a primeira tese produzida no Brasil sobre relações raciais, "Estudo de atitudes raciais de pretos e mulatos em São Paulo", sob a orientação de Donald Pierson, na Escola Livre de Sociologia e Politica. Ela utiliza entrevistas e apresenta o depoimento de 31 pessoas "negras e mulatas" distribuidas conforme classe social, condição econômica, profissão e nível de instrução².

\footnotetext{
${ }^{2}$ BRAGA, Ana Paula Mussati. Pelas Trilhas de Virginia Bicudo : psicanalise e relaçoes raciais em Sao Paulo. Revista Lacuna - uma revista de psicanalise, 06/12/2016, numero 2, ISSN - 2447-2663.
} 
A historia da psicanalise no Brasil se confunde com as ações e protagonismo pioneiro de uma mulher de origem negra, filha de imigrante italiana com descendente de africanos escravizados nascido no período da Lei do Ventre Livre: seu nome Virginia Leone Bicudo.

“(...) mas como pensar que uma instituição que se cria com a participação de psicanalistas leigos que trabalham com estudantes de escolas publicas de São Paulo, fora do setting analítico tradicional, e que traz dentro do seu quadro, entre os seus membros mais importantes, uma mulher negra, prefere deixar essa questão da negritude como algo que, quando muito, estaria reservado ao passado de Virginia?" (Braga, 2016). ${ }^{3}$

Por esta passagem da consideração sobre a personalidade de uma grande expressão intelectual negra no Brasil no cenário psicológico da saúde mental, observamos que o percurso histórico dos fatos realizados por mulheres, principalmente as mulheres negras, são apagados do contexto intelectual e formativo da sociedade e por extensão nas ciências, nas epistemologias, nas universidades, que são instituições de disseminação de conhecimento e transmissão de saber.

A formação de uma epistemologia psicológica é uma construção formativa de âmbito e relevância curricular. Porque atesta e valida a legitimidade do que é primordial para a ação do campo da práxis e reflexão - desenvolvimentos da carreira e do exercício - do profissional de psicologia.

Assim sendo, o apagamento das marcas da população negra nos territórios epistemológicos da ciência psicológica, reproduz a ordem social de um racismo, machismo, sexismo e violência diante das mulheres, das mulheres negras, dos protagonistas negros presentes e atuantes no contexto da academia e universidades brasileiras.

Esta introdução sobre a presença marcante de Virginia Bicudo não se deu apenas na psicanalise e psicologia no Brasil. Mas também e inicialmente na ciências sociais.

Ela, Virginia, mulher negra, foi a única intelectual negra e feminina a fazer parte dos grandes pensadores e sociólogos que compuseram o importante projeto Unesco, o qual financiou valiosas investigações cientificas no Brasil sobre relações étnicas e raciais; tendo Oracy Nogueira, Florestan Fernandes, Otavio lanni, Roger Bastide, entre outros como referencias importantes das pesquisas sobre a temática no cenário nacional ainda hoje. No entanto, o apagamento da presença de Virginia ocorre também no contexto sociológico.

Esse projeto, conhecido como Unesco-Anhembi, transformou-se num divisor de águas na temática, provocando o declínio do mito da democracia racial. A pesquisa de Virgínia (como a de Oracy Nogueira e Aniela Ginsberg), apesar de fundamental e independente, foi

\footnotetext{
${ }^{3}$ Idem, ibidem. p.7.
} 
publicada em 1955 como se fosse um "apêndice" do estudo e a apresentação do livro acabou por colocar Roger Bastide e Florestan Fernandes como organizadores. Ainda pior foi o que se passou com a segunda edição, de 1959, em que as pesquisas de Bicudo, Nogueira e Ginsberg foram retiradas completamente da publicação. Florestan Fernandes, trinta anos depois, explica o que ocorreu como um "lapso editorial", mas o efeito para a história dessa publicação é que esse importante estudo será lembrado como obra exclusiva da "escola paulista" da Universidade de São Paulo, em detrimento da produção dos autores da Escola Livre de Sociologia e Política (Braga, 2016).

Fazer parte da Escola Livre de Sociologia e Politica, foi opção pessoal de Virginia Bicudo. Que observou que sua inscrição e possibilidades de desenvolvimentos de modo menos exposto a violência do racismo em São Paulo em termos intersubjetivos era mais viável. No entanto, o elitismo da universidade de São Paulo, que o representa ainda hoje, é sobreposto sobre o conhecimento produzido na mesma esteira de desenvolvimentos da escola de sociologia e politica do qual Bicudo, Ginsberg e Nogueira faziam parte.

No fragmento das biografias das pessoas, observamos os impactos das injustiças e violências do sistema racial e classista impregnado na sociedade brasileira. Aspecto originário da estrutura hierárquica "servo-senhor", que são os alicerces intrínsecos da formação social do Brasil: ou seja, a relação de subalternidade ao regime escravista, escravocrata e colonial; legitimando e naturalizando a desigualdade sócio-econômica, cultural e politica (cor, gênero, faixa etária, pertencimento étnico).

Sob esta circunstancia a vida de Virginia é trazida neste artigo para referendar que os modos de organização curricular e desenvolvimentos da ciência psicológica estão subordinados e reproduzem-se a partir de relações de poder, colonialismo e racismo presentes na sociedade brasileira em pleno século 21. Pois conforme observaremos adiante, os currículos pouco ou nada referem a importância da relação étnica e racial para a formação especifica do psicólogo brasileiro, como também em termos nacionais não reconhece a validade de nomes emblemáticos na psicologia, psicanalise e ciências sociais de personalidades como Virginia Bicudo.

O mesmo se passa com Frantz Fanon no cenário francês e internacional no campo da medicina. Seus estudos singulares e referências inaugurais para pensar o psiquismo do sujeito violentado pelo jugo do colonialismo europeu é considerado nas universidades de medicina. No entanto, os médicos em formação, mal sabem que Fanon era um médico psiquiatra que rompeu com a tradição de pensar a medicina psiquiátrica distante das relações e conexões com a 
interpretação do contexto social. Seu nome é associado a um militante negro da Martinica sobre questões voltadas para a historia e sociologia (Macey, 2013) . $^{4}$

De todo modo, ainda que pouco o nome de Fanon é modestamente considerado no cenário médico da psiquiatria no qual ele esteve militando de modo engajado, intelectualmente produtivo e profissionalmente ativo em Paris, Lyon e na Algéria - o pais que preferiu adotar por pátria em negativa e abdicação de sua identidade originariamente francesa dos territórios ultramarinhos das Antilhas (no caso a Martinica).

Explanar sobre a vida destes sujeitos, mulher e homem negro, intelectuais grandiosos do campo psíquico e social, na construção de epistemologias que representam outras modalidades de pensamento distinto da hegemonia branca europeia, como Bicudo e Fanon, é debater e refletir sobre os pilares constitutivos da psicologia brasileira e mundial e considerar a presença massiva de aportes que são coniventes com a ordem da injustiça, desigualdade, violência e apagamento da importância das relações étnicas na formação do pensamento contemporâneo nas ciências da saúde e do psiquismo humano.

Sob tal perspectiva, o currículo em psicologia esta alienado ao colonialismo europeu. As condições do pensamento dominante de uma ciência que se organiza por relações de poder e sobreposição de ideologias e pessoas.

Virginia, embora no mesmo período contemporâneo e com atitudes de vanguarda e pioneirismo feminino na psicanalise e psicologia como François Dolto, vale menos que esta, no cenário intelectual de produção mundial e nacional.

Os psicólogos brasileiro pouco precisam se esforçar para saber de Françoise Dolto, psicanalista francesa, articuladora da difusão da psicanalise para o publico leigo, escrevendo e ministrando palestras em rádios. Virginia Bicudo teve um percurso semelhante em termos de atuação social e profissional e valor de inscrição para a psicanalise e psicologia brasileira. No entanto, nos currículos que prescrevem literaturas sobre psicologia e psicanalise, ela no Brasil é uma desconhecida. A francesa Dolto, nos currículos das universidades de psicologia no Brasil, é em geral considerada nas bibliografias das disciplinas.

Igualmente, Stuart Hall é um gigante intelectual da contemporaneidade, que revolucionou os estudos culturais. Na França, apenas agora no século 21, Frantz Fanon é considerado no mesmo patamar de pensamento e gigantismo de Hall ${ }^{5}$. Stuart que é inglês, é traduzido e reconhecido em diferentes países no campo da ciência e da academia sociológica, antropológica e histórica. Fanon,

\footnotetext{
${ }^{4}$ MACEY, David. Frantz Fanon : une vie. La Découverte, Paris, 2013.

Colloque Une Journée avec Stuart Hall , Université Paris-Diderot, Paris, 11/05/2016.
} 
que recusou a nacionalidade francesa, é pouco conhecido em seu pais de origem e atuação (a França) embora traduzido em todo o mundo. Ainda assim, no campo de sua formação especifica, que direcionou os escritos de seu pensamento e engajamento social - a medicina psiquiátrica Fanon é um desconhecido no mundo e no Brasil. Principalmente no campo da saúde e da psicologia.

No Brasil Fanon é abordado e conhecido pelo movimento negro. Que conectado com as produções importantes do mundo sobre colonialismo, cultura, relações étnicas e raciais, trouxe para a academia - ciências sociais, historia e antropologia - os estudos de Fanon. Embora na sociologia norte-americana Fanon seja um dos grandes ícones dos estudos culturais, colonialismo e relações étnicas, em terras brasileiras alguma visibilidade que Fanon auferiu dentro da academia formal no Brasil se deu apenas a partir de escritos e produções de intelectuais negros vindos da militância politica do movimento negro.

A localização geográfica dos corpos humanos e suas produções são reconhecidas e visibilizadas conforme seu pertencimento étnico e localização no espaço. E sob tal tratamento esta subordinada a condição do desenvolvimento do pensamento, desenvolvimento do processo cultural civilizatório e por consequência a organização didática da epistemologia formativa presentes nos currículos profissionais em saúde, como é o caso da psicologia.

O currículo no curso de psicologia possui esta condição de principio politico e ideológico e sob estas normas hegemônicas de forças sociais se constrói a relação com o que é digno e valido de ser considerado e indicado para a formação do campo profissional consolidado. Embora a psicologia não seja ciência da saúde, ela esta em relações constantes com a interdisciplinariedade e multidisciplinariedade das ciências e profissões do campo da saúde. E nesta perspectiva o hermetismo tecno cientifico das epistemologias em saúde preterem a validade dos conhecimentos do campo das relações étnicas e raciais no contexto brasileiro.

Nos paradigmas das sociedades cientificas do mundo europeu e norte americano esta condição não é similar. Ela é oposta e em direção ascendente na importância de saber sobre as diferenças, alteridades, contextos de vida histórica e antropológica distintas das predominantes no classicismo da inscrição acadêmica. Auferindo os estudos sobre relações étnicas, diferenças, cultura, impactos e violências colonialistas, analises sobre contextos de imigração e migração, cada vez mais importantes de serem aprofundados e transmitidos na formação do profissional das ciências humanas e da saúde.

Munanga, em 2000, afirmou que o contexto norte americano investe maciçamente em pesquisa e formação para as relações étnicas e raciais. Enquanto que o contexto brasileiro, no que 
tange a psicologia, silencia sobre a necessidade de discussão interna da ciência da psique humana. Dizia ele: Qual é a explicação dessa ausência e desse silêncio (da psicologia) sobre um tema que toca a vida de mais de 60 milhões de brasileiros de ascendência africana? ${ }^{6}$

Embora a partir dos anos 2003, com a alteração da Lei de Diretrizes e Bases da Educaçao Brasileira, Lei 10.639/03, que torna obrigatório o ensino de Historia da Africa e Cultura da Civilizaçao Africana nas escolas brasileiras, cria-se, a partir da luta e conquista do movimento negro, dispositivos sociais formativos no ensino superior principalmente na pos-graduaçao de formação profissional para professores e educadores da escola básica. Este dispositivo acaba por impactar positivamente a produção psicológica brasileira, até então comodamente inerte frente as demandas psíquicas e emocionais da população brasileira (negra em seu conjunto majoritário, conforme IBGE, 2010).

Os componentes curriculares dos cursos de pos-graduaçao e formação de cursos específicos destinados a preocupação com este publico - a população negra e indígena (inclusão à Lei 10.639/03, da cultura e civilização indígena a partir da lei 11.645/08), passam a agregar considerações formativas importantes em disciplinas e exigências na formação do quadro docente no ensino superior inclusive.

Ainda assim, para o nível da graduação, inicio primordial de formação do profissional de psicologia, as lacunas na composição das disciplinas obrigatórias de conteúdos voltados para as relações étnicas e raciais são ainda visivelmente existentes.

Em nossos estudos, observamos que no currículo organizado no ano de 2015 em uma das universidades do nordeste brasileiro, existe o componente curricular obrigatório de psicanalise lacaniana. No entanto, não há neste currículo formativo em psicologia, em instituição sediada em território onde mais de $74 \%$ da população é negra (pardos e pretos, IBGE, 2010), nenhum componente curricular obrigatório sobre psicologia e relações étnicas e raciais.

Com base neste dado de nossa pesquisa a pergunta de Munanga continua valida ha quase duas décadas passadas de suas provocações aos psicólogos brasileiros.

Cabe observar que na validade dos corpos - "a carne mais barata do mercado é a carne negra" - os corpos em sua territorialidade especifica e composição de atributos fenotípicos, culturais e étnicos, tem seu valor de estar disposto nos grandes shoppings e boutiques de grifes das grandes academias da ciência brasileira. Por conta disto a psicanalise francesa (representada por Françoise Dolto) é indiscutivelmente bem considerada no mundo como valorosa na difusão

\footnotetext{
${ }^{6}$ MUNANGA, Kabenguele. Entrevista concedida a Antonio da Costa Ciampa. Revista ABRAPSO, Psicologia e Sociedade; $12(1 / 2): 5-17 ; j a n . / d e z .2000$, p.05.
} 
intelectual e acadêmica da psicologia. Igualmente os estudos ingleses sobre cultura e relações étnicas e colonialismo (representado por Stuart Hall) são referências para o cenário global na antropologia e estudos sobre identidade na contemporaneidade.

A mais valia, o preconceito, a desigualdade, a injustiça referendam as condições de economia e organização do currículo formativo na graduação em psicologia e saúde mental. A colonização no território das Américas portuguesas e espanholas ainda possui força de catequização e dominação nos enredos discursivos e epistemológicos daqueles que constroem o currículo em psicologia: professores e psicólogos nas academias brasileiras.

Os impactos e violências psíquicas decorrentes do racismo, da diferença, da desigualdade social, da submissão das culturas, são inegavelmente objetos de estudo da psicologia e da psicanalise.

Virginia Bicudo e Frantz Fanon foram intelectuais e pensadores negros que em seus tempos foram contemporâneos de pessoas que escreveram e pensaram similaridades de seus contextos. Foi o caso de Françoise Dolto, contenporanea de Virginia Leone, e Maud Manoni, contenporanea de Frantz Fanon.

No entanto, enquanto Manoni e Dolto são presenças consideradas no universo nacional e internacional da psicologia e psicanalise, Virginia Bicudo e Frantz Fanon são simples desconhecidos.

O racismo institucional no que tange a territorialidade da presença dos corpos na geografia do globo - os espaços e territórios de poder acadêmico internacional - adicionado a condição do pertencimento étnico como no caso de Virginia e Fanon, sera decisivo na visibilidade destes pensadores nos contextos de poder epistemológico. Inegavelmente, fazer e discutir currículo na academia mundial são circunstancias de disputa de poder.

A violência e o impacto marcou a obra das psicanalistas Virginia Leone Bicudo e Maud Manoni, assim como a experiência dolorosa da negritude e da perversão colonialista na pele de Fanon e Stuart Hall.

A vida numa sociedade multicultural, o contato com um universo colonial e a experiência subjetiva dolorosa no seio de uma família na qual predominava a ausência de um amor verdadeiro levaram-na a se interessar por todas as situações de violência e ruptura: como reatar com a língua perdida da infância? Como superar os traumatismos inerentes a todas as formas de separação, a fim de libertar-se por meio da criação ou da integração? Estas 
eram as questões que ela se punha ao chegar a Paris, depois de viver algum tempo em Nova York (Roudinesco, 1998) ${ }^{7}$.

Igualmente Virginia Bicudo informa em entrevista a

Eu fui criada fechada em casa, quando saí foi para ir à escola e foi quando, pela primeira vez, na escola, a criançada começou: negrinha, negrinha. Quando eu estava em casa, eu nunca tinha ouvido. Então eu levei um susto. (Entrevista de Virgínia a Anna Verônica Mautner e Luiz Meyer, outubro de 1983). Eu me interessei muito cedo por esse lado social. Não foi por acaso que procurei psicanálise e sociologia. Veja bem o que fiz: eu fui buscar defesas científicas para o íntimo, o psíquico, para conciliar a pessoa de dentro com a de fora. Fui procurar na sociologia a explicação para questões de status social. E na psicanálise, proteção para a expectativa de rejeição. Essa é a história. (Virgínia Bicudo, entrevista a Anna Verônica Mautner, 1998) ${ }^{8}$.

Fanon também nos informa:

A explosão não terá lugar hoje. É muito cedo ou muito tarde.

Eu estou desarmado de verdades decisivas (...)

Com toda serenidade é preciso que algumas coisas sejam ditas. Estas coisas eu vou dizer, não vou grita-las. Pois há muito tempo o grito saiu de minha vida. (...).

Há muita imbecilidade nesta terra. E por isto eu digo que trata-se de provar.

Para um novo humanismo...

A compreensão dos homens...

Nossos irmãos de cor...

Eu creio e ti, Homem...(ser humano)

O preconceito de raça...

Compreender e amar

(...) Em uma so palavra a questão negra se despojara de toda sua problemática.

(...) O negro não é um ser humano. É uma zona de não ser, uma região extraordinariamente estéril e árida, uma descida essencial de acesso profundo, de onde um verdadeiro nascimento poderá surgir (Fanon, 1954) ${ }^{9}$.

Stuart Hall, refere em alguns escritos biográficos e entrevistas concedidas no contexto inglês de sua trajetória de pesquisador, militante negro e acadêmico, que as bases para suas pesquisas e direções de estudos em cultura, identidade e colonialismo foram originarias das reflexões e sentimentos vividos em sua infância. Ele era filho de um casamento inter-racial e entre os filhos do casal ele era o mais negro. O de pele mais retinta. Isto no contexto familiar e comunitário o fazia ser preterido em algumas circunstancias. E seus pais desejavam que ele, assim

\footnotetext{
${ }^{7}$ ROUDINESCO, Elisabeth. Memoria. A psicanalise de feiçoes humanas. Folha de São Paulo, 12/04/1998.

${ }^{8}$ BRAGA, Ana Pauloa Mussatti. Pelas trilhas de VirginiaBicudo: psicanalise e relaçoes raciais em Sao Paulo. Revista Lacuna - uma revista de psicanalise, 6/12/2016, n. 02, ISSN - 2447-2663.

${ }^{9}$ FANON, Frantz. Peau noire, masques blancs. Editions du seuil, Paris, 1952, p.5-6.
} 
como os demais irmãos realizassem estudos nas áreas clássicas de poder social de prestigio como as engenharias, medicina ou direito.

Observador que era de suas condições de diferença dentro de seu próprio contexto familiar comunitário Hall desenvolveu arguta sensibilidade para os problemas do colonialismo no cerne da cultura e formação da identidade das populações negras ${ }^{10}$.

Observamos que a grandeza dos estudos sobre o negro, o colonialismo, o sofrimento e impacto do racismo, do escravismo forçado, da violência da dominação do europeu branco são questões fundamentais da sociedade contemporânea e estão no cerne das discussões em saúde, psiquismo, desenvolvimento politico e social.

O currículo do campo da saúde necessariamente precisa considerar e agregar em seus componentes específicos os escritos de Virginia Leone Bicudo no Brasil e Frantz Fanon no mundo europeu, assim como outras referencias importantes para o desenvolvimento do trabalho e pesquisa do profissional de psicologia junto a população brasileira de $51 \%$ pretos e pardos (IBGE, 2010).

No trabalho que ora realizamos observa-se a interseç̧ão entre psicologia social, psicologia clinica psicanalítica e relações étnicas e raciais.

A partir das bases literárias disponíveis sobre o tema, bem como levantamento dos relatórios finais de estagio em psicologia de duas universidades do nordeste brasileiro iniciamos os apontamentos das analises parciais. Neste artigo apresentamos alguns dos conteúdos referentes ao campo empírico de uma das universidades participantes da amostra, considerando que ainda estamos em fase de coleta desta primeira amostra.

A partir de discussões em eventos de extensão e ensino sobre os impactos e efeitos do racismo promovidas no contexto do núcleo de pesquisa através das leituras realizadas, observamos que o racismo é um fenômeno complexo presente na sociedade desde sempre. Por meio de estruturas sociopolíticas o racismo construiu um mito que mantém o negro e as populações não brancas em condição de inferioridade material (econômica e financeira) e gera prejuízos graves à saúde emocional e equilíbrio psíquico das pessoas que o sofrem.

A participação da academia brasileira, a partir da década de noventa (Consorte, 1991), conseguiu agregar força ao debate epistemológico nas ciências sociais, historia, serviço social, educação e outros campos disciplinares, que passaram a fazer frente a esta condição de racializaçao do negro brasileiro a partir da expressão de intelectuais e pensadores e cientistas negros que passaram a protagonizar os estudos sobre o negro e a população negra no Brasil. A

\footnotetext{
${ }^{10}$ Colloque Une Journée avec Stuart Hall , Université Paris-Diderot, Paris, 11/05/2016.
} 
formação pelos movimentos sociais negros, anteriores a presença de profissionais de pesquisa no contexto acadêmico serviu de alicerce fundamental para a produção escrita e intelectual da pesquisa universitária até então restrita aos campos clássicos das ciências sociais e ciências sociais antropológicas.

O campo médico com Raimundo Nina Rodrigues, através da fundação no contexto nacional da ideologia do racismo à população negra, foi o protagonista por difundir a ideia pseudocientifica da inferioridade intelectual do africano escravizado no Brasil. E sob esta consideração os campos da saúde e da psicologia sempre estiveram alheios a buscar paradigmas que contestassem estas noções difundidas no contexto acadêmico e politico do Brasil de 1900 (Oliveira, 2016) ${ }^{11}$.

A luta do movimento negro contra estas ideologias racistas no Brasil, inspirados nos movimentos de luta pelos direitos civis nos Estados Unidos a partir das décadas de 30, 40, 50 e 60, com as ações de Rosa Parker e Martin Luther King, na marcha pela paz e contra o racismo, possibilitaram a pressão e resistência dos movimentos sociais negros no Brasil (Oliveira, 2008) ${ }^{12}$.

O conceito de negritude, inaugurado no contexto europeu francês a partir de pensadores negros da diáspora, como os Aimé Cesaire, poeta e politico e Frantz Fannon, médico psiquiatra, também fizeram ecos importantes no contexto norte americano e no Brasil. Estes alicerces epistemológicos de autores como estes foram divulgados e estudados fora da academia pela militância do movimento negro. Isto legou aos intelectuais negros brasileiros importantes bases para conceber políticas que visam combater o racismo na sociedade mundial e contribuir de modo importante para compreender, contestar e enfrentar a presença constante desse grave problema que é o racismo nas sociedades globais (Oliveira, 2008) ${ }^{13}$.

$\mathrm{Na}$ analise das literaturas disponíveis sobre o tema observamos que os interesses políticos ideológicos de um grupo minoritário de sujeitos sociais tem favorecido para a manutenção de um status quo da sociedade, reforçando uma ideologia de supremacia racial branca que ainda nos tempos atuais no século 21 consegue se sobrepor e se manter.

Percebe-se que apesar de todo esforço, toda articulação política, os espaços sociais para debater sobre o fenômeno do racismo como produto de adoecimento psíquico entre negros e brancos, fator gerador de exclusão e genocídio da população negra, ainda é ínfimo, restrito e pouco valorizado - apoiado.

\footnotetext{
${ }^{11}$ OLIVEIRA, Regina Marques de Souza. Cenarios da saúde da população negra no Brasil - diálogos e pesquisas, Fino Traço/EDUFRB, 2016.

12 OLIVEIRA, Regina Marques de Souza. A identidade de jovens negros nas periferias das metropoles: retratos entre Sao Paulo e Paris (Tese de Doutorado em Psicologia, PUC/SP), 2008.

${ }^{13}$ Idem. Ibidem.
} 
Quando há esta alguma abertura para o dialogo sobre diferenças, violências raciais, direitos e injustiças, o debate é percebido e considerado como problema exclusivo da população negra e um "problema de racismo do próprio negro que se inferioriza".

No contexto escolar em geral é possível perceber que muitos que não se consideram negros acreditam que o problema do racismo tem a ver com o próprio negro, com o seu sentimento de baixa auto-estima e inferioridade. No entanto esta é uma patologia do branco, que transfere para o outro - o negro - a problemática de seu complexo de superioridade (Souza, $2003)^{14}$.

E a ciência no Brasil, sobretudo a psicológica, que fundou-se na logica higienista e racializada de Raimundo Nina Rodrigues, tem se organizado coerentemente com estas praticas alienistas e de segregação (Oliveira, 2016).

$\mathrm{Na}$ ainda jovem historia da psicologia no Brasil, considerando que enquanto profissão ela possui apenas 55 anos de regulamentação (Antunes, 2014), observamos que há uma normativa estruturante que por vezes traz um aspecto de cientificidade e que robustece a ideologia de perpetuação da inferioridade da população negra. É importante destacar que essa ideologia traz suas raízes do período colonial, marcado também pela pré-cientificidade da psicologia no Brasil.

É diante desse contexto que Antunes (2014) vai afirmar que um olhar voltado para os fenômenos psicológicos que marcaram presença no Brasil colonial. Vale salientar ainda, que os autores da psicologia, em sua grande maioria, eram portugueses e/ou jesuítas. E que algumas áreas do conhecimento tais como teologia, medicina, arquitetura, moral e política se debruçaram sobre o saber psicológico. Estes saberes produzidos se coadunavam com os interesses da metrópole portuguesa e européia. Assim sendo, em tese, foi o pensamento psicológico formulado nesse período que embasou a construção histórica da ideologia da inferioridade intelectual da população negra no Brasil.

Sob tal consideração, a psicologia, hoje no século 21 ainda relativamente silente sobre suas responsabilidades epistemológicas, éticas e profissionais diante da grave situação de violência e injustiças historicamente direcionadas as populações negras no Brasil, foi a responsável por fundar, de certo modo as bases desta ideologia racializada nas ciências e senso comum da sociedade brasileira.

Grosso modo, o que pode-se postular é que têm-se uma ciência construída por indivíduos extremamente moralistas e impregnados de um pensamento europeu. E foram justamente esses

\footnotetext{
${ }^{14}$ SOUZA, Regina Marques de. Sobre crianças no espaço hibrido da esperança: reflexoes da psicologia social e da psicanalise ( Dissertaçao de Mestrado em Psicologia, PUC/SP), 2003.
} 
sujeitos, que escreveram e difundiram o que era considerado valido para a psicologia; trazendo concepções que não se enquadravam à realidade dos povos que aqui viviam, ou seja, os indígenas. Os quais foram tratados também como selvagens, inferiores, racializados, tal qual como se produziu a violência psíquica sobre os sentidos de ser negro em um pais como o Brasil.

Outro aspecto importante apresentado por Antunes ${ }^{15}$ sobre a constituição historica da psicologia no Brasil, é a seleção de temas abordados no período pré- institucional da Psicologia. Destaca-se nestes temas a capacitação para o trabalho, a adaptação ao ambiente, as diferenças raciais, a aculturação e técnicas de persuasão de "selvagens".

Observe-se que "persuasão de selvagens" constituía-se como um elemento fundamental para o alicerce da psicologia enquanto estudo do comportamento. Fundamental porque produzia as bases ideológicas de violência e dominação dos povos presentes no território brasileiro e possibilitava organizar metodologicamente - diga-se cientificamente - as formas de impor a submissão e escravização da população indígena no Brasil e posteriormente a escravização do africano denominado negro.

Analisamos que a apropriação desses conceitos faziam parte da base de interesse da psicologia colonial. Esta psicologia foi trazida para as terras brasileiras e este aspecto no dà indícios de uma psicologia legitimadora das práticas racistas excludentes e que a preocupação com os temas acima citados serviram como um mecanismo de exploração dos povos indígenas e africanos escravizados que objetivava a manutenção e sustentação material e econômica da classe branca europeia portuguesa. Os privilegiados pelo poder e domínio pela violência física castigos/força - e psíquica ( a propagação pseudo cientifica de superioridade racial branca e inferioridade negra e indígena).

Esta vinculação da psicologia às artimanhas do poder e dos interesses políticos é um fato verídico e obscuro na constituição desta ciência no Brasil. Os interesses da psicologia revelam uma ciência que serve inauguralmente no Brasil ao controle, ao mandato pelas autoridades vigilantes pela ganância e acumulo econômico e financeiro a partir do martírio dos corpos alheios considerados ideologicamente como inferiores e não humanos.

Neste trabalho realizamos a interpretação da raiz historica da psicologia por estas bases, pois,

Essa situação exigiu a organização de um forte aparelho repressivo de um lado, e de outro, um solido aparato ideológico, sustentado pela Igreja Catolica, cuja função precípua era

\footnotetext{
${ }^{15}$ ANTUNES, Mitsuko Aparecida Makino. A psicologia no Brasil - leitura historica sobre sua constituiçao. EDUC/São Paulo, 2015.
} 
transmitir e manter uma ideologia que, em ultima instância, legitimasse a exploração da colônia (Antunes, 2014, p.21).

E sob esta organização jesuítica é inegável o papel da ciência psicológica que se construiu para sustentar este aparato politico e religioso. Aparato este muito mais politico e econômico que propriamente religioso.

É diante desse contexto que a pesquisa questiona e suscita a consideração sobre os currículos das Instituições de Ensino Superior no Brasil.

Segundo o censo 2010 do IBGE, o Brasil aponta uma proporção de 54\% de população negra (pretos e pardos) autodeclarados.

Se os dados estatísticos assim se revelam quanto ao perfil de sua população majoritaria, por quê razão as relações étnicas e raciais não acompanham o itinerário formativo de estudantes universitários dos cursos de psicologia no Brasil?

Ainda consideramos: Porque os profissionais que organizam e elegem os componentes curriculares na psicologia não se preocupam com as comunidades quilombolas e indígenas existentes no território brasileiro?

Porque a população indígena e negra que contribuí para a formação da identidade do povo brasileiro não é presente epistemologicamente nos currículos de formação do psicólogo em nossa realidade?

Ao compararmos os currículos de uma universidade publica no contexto do nordeste brasileiro em suas duas versões existentes (2007 e 2015), os quais foram ajustados à realidade do território que esta instituição esta instalada, observamos no conjunto dos componentes curriculares ofertados ao aluno que ambos os currículos negam discutir a importância da presença da população negra e indígena no contexto da sociedade brasileira.

Os componentes curriculares observados no projeto politico e pedagógico do curso de psicologia em suas duas versões, uma inaugural em 2005/2007 e outra mais amadurecida em 2015, apresentam de modo genérico os mesmos interesses pelas epistemologias clássicas que compõem o edifício da ciência psicológica.

Obviamente como toda universidade deve pretender-se minimamente semelhante aos conhecimentos basilares de seu campo, importante seria inserir no currículo as perspectivas especificas do contexto no qual ela esta inserida. No entanto, observando os dois currículos, embora apontem para esta perspectiva diferencial da origem de localização no território geográfico da instituição e perfil do alunato, na observação da grade dos componentes curriculares ofertados não há nenhuma disciplina que aborde dentro da formação especifica do 
psicólogo as relações culturais, étnicas, psicológicas e sociais da população negra e indígena brasileira.

Embora o teor do currículo de 2007 expresse possuir como desafio central, a construção de uma identidade própria nessa nova instituição de ensino de terceiro grau e buscar promover o desenvolvimento e formação do cidadão a partir da valorização das culturas locais e dos aspectos específicos do ambiente físico e antrópico" (PPC, Psicologia, 2007, p.2), nada se observa no referente a disposição da grade de componentes um único titulo de disciplina que seja referente a população negra ou indígena.

A cidade onde esta localizada a instituição em questão possui conforme o IBGE (2010), um índice de $74 \%$ de população negra (pretos e pardos) majoritariamente presente no território e entorno institucional.

No entanto o primeiro currículo em 2007 (projeto politico e pedagógico do curso de psicologia) não contempla o trabalho do psicólogo voltado para a compreensão étnica e cultural desta população.

Em 2007, o território do entorno universitário é invisível para os docentes que organizaram o projeto, politico e pedagógico do curso.

Sendo assim, também consideramos na analise do conteúdo formal do PPP que é valorizada a superioridade de um único grupo étnico: o branco.

Neste sentido o PPC da psicologia nesta instituição, ao invisibilizar o indígena e o negro africano em se curriculo, reitera a omissão da psicologia em relação a importância destas populações para a compreensão do sofrimento psíquico e saúde emocional do brasileiro.

A negação dos problemas sociais decorrentes das relações patológicas entre o senhorio branco do engenho e fazendas agrícolas do Brasil colonial e a negação do indígena e do africano negro escravizado como sujeito humano, psíquico e social estão presentes na noção do PPC do curso de psicologia da universidade estudada, pois ao invisibilisar estas populações presentes em mais da metade de seu entorno territorial (74\%) obedece-se à logica colonialista de prevalecer o paradigma ideológico da desejada superioridade da brancura.

Sendo assim, estão configuradas as formas de subjetividades forjadas na diferença que é considerada enquanto inferioridade. Estas subjetividades e formas de sociabilidades reproduzem antigos preconceitos e patologias que influenciam a formação dos currículos acadêmicos que deste modo fixam-se ao mito da democracia racial na perspectiva de Gylberto Freyre, que classicamente é considerada como a mais viável identidade brasileira (Oliveira, 2016). 
No entanto, as raízes e a violência do racismo estão no cerne do cotidiano psicossocial de brancos e negros e manifesta-se através do racismo institucional no não acesso aos melhores postos de emprego, impedimentos para promoção na carreira mesmo quando a qualificação é superior a de uma pessoa não negra, a violência obstétrica prevalente em mulheres negras no acesso reduzido as condições de saúde em situações por exemplo de pré natal e parto, circunstância em que as mulheres brancas possuem maior acesso a consultas médicas, anestesia para o parto, melhor forma de atendimento pelo médico ou profissional de saúde, enfim. Assim, é fundamental para a psicologia o estudo sobre o relações étnicas e racismo.

Neusa Santos Souza escreveu um clássico na psicologia dos processos subjetivos e racismo. O livro Tornar-se Negro (1983), aborda estudos sobre o mito negro como fruto de convergências, acordos políticos, econômicos e ideológicos que reverberam socialmente e que naturalizam relações sociais de extrema violência. Estes aspectos foram afirmados como acima dissemos por uma psicologia inscrita em bases coloniais que visava à dominação, a doutrinação, isto é, a depreciação da população negra, quer seja pela desqualificação das características fenotípicas, quer seja pela destituição de sua condição de humanidade, pois, para os brancos europeus, apenas eles são representantes dignos da espécie "raça humana".

Entretanto os mecanismos de subjugação da população negra não são percebidos como normativa- estruturante de uma patologia da sociedade. O problema é atribuído como "problemática dos negros". Esta ideologia escamoteia a presença dos sujeitos brancos na disseminação das violências raciais. A sociedade não quer ver e responsabilizar-se diante destas ações sórdidas e cruéis praticadas pelos brancos e prefere, por sua omissão, o silenciamento.

Esse sistema de ideias perverso repercute sobre o processo de identificação de negros e brancos pois o a identificação do negro é tão desvalorizada, que esta reverte-se sempre em sofrimento histórico, étnico e pessoal para o sujeito ${ }^{16}$.

Haja vista, que o modelo identificatório, ou seja, o modelo universal de beleza, civilidade, da razão estão atreladas as pessoas não negras e o que se distancia deste modelo é considerado inferior. Então esse referencial inadequado de representação de humanidade é responsável pelo sofrimento psíquico do racismo.

Nesse sentido, a naturalização dessas ideias banalizam e negam o sofrimento psíquico causado pelo racismo do branco. Essa dor não é fruto de fantasias inconscientes. Ela é realidade latente que priva a população negra de ter acesso emocional ao prazer. As consequências disto é a

${ }^{16}$ COSTA, Jurandir Freire. Violência e Psicanalise.Graal, Rio de Janeiro, 1984. 
negação da cultura negra e a dificuldade de enfrentar a violência branca que incessantemente persegue seu corpo físico e psíquico com tanta depreciação moral de forma naturalizada.

Carone e Bento (2002) explicam que o branqueamento é um mecanismo criado pelos brancos na perspectiva de culpabilizar os negros pela situação de vida na qual estão submetidos. Os brancos apesar de reconhecerem as desigualdades sociais não se percebem no papel de algoz. E mais uma vez é um acordo formalizado que exime o branco da responsabilidade civil e moral da barbárie que pratica contra a majoritária parcela da população negra.

$\mathrm{O}$ acesso e formulação de um currículo formativo adequado em psicologia deve considerar esta esteira de estudos aqui brevemente apresentados. É fundamental que a psicologia aprofunde estudos sobre branquitude que é a manutenção do privilégio estrutural das pessoas brancas que ocupam espaços de comando e de poder a fim de reproduzir incessantemente hierarquias verticalizadas, ao gosto das relações colonialistas e escravizadoras, as quais são estão revestidas como méritos obtidos por seus esforços e qualidades individuais. Nada mais enganoso e perverso, pois os sujeitos humanos negros não possuem os privilégios psíquicos e materiais de incontestavelmente serem portadores do "direito de serem considerados iguais entre os iguais". Os estudos sobre a emocionalidade negra e branca nas relações étnicas da contemporaneidade da sociedade brasileira e mundial é um esforço formativo em ensino, pesquisa e extensão em psicologia que deve ser almejada por todos os profissionais do campo da saúde mental. Os resultados parciais da pesquisa a partir da analise e investigação dos currículos vigentes e projetos políticos e pedagógicos da universidade pesquisada (PPP 2007 e PPP 2015) nos revelam que: a) o currículo formativo inaugural da universidade reproduz o desprezo a população negra na formação do profissional de psicologia, como em geral ocorre nas grandes universidades tradicionais do Brasil; b) em sua segunda oportunidade de desfazer o erro, a instituição também, conforme o teor do documento, não se preocupou em garantir componentes curriculares que expressem a temática saúde, psicologia e relações raciais. No levantamento dos temas abordados nos relatórios finais de estagio em psicologia (trabalhos de conclusão de curso de psicólogos formados pela instituição estudada) durante o período de uma década de investigaçao (2006 a 2016), os resultados parciais da pesquisa são: a) constam em assustadora primazia a preocupação com temas psicanalíticos lacanianos, típicos do interesse de uma clinica individual de consultório; b) em segunda perspectiva há trabalhos na área escolar que revelam alguma preocupação com as questões relativas a formação do psicólogo e o campo social; c) Sobre nosso interesse investigativo, a temática relações étnicas e raciais, o tema aparece apenas a partir do ano de 2012, 
2014 e 2015 - uma produção por ano. Ou seja, apenas três (03) trabalhos sobre a temática durante 11 anos de existência do curso de psicologia na instituição pesquisada.

De modo geral esta analise parcial dos dados, os quais ainda não foram totalmente computados, nos permite considerar que a psicologia brasileira em sua formação na contemporaneidade do século 21 reproduz no Brasil, em sua formação de base para o exercício profissional (graduação) reproduz o padrão descompromissado com a população brasileira em seu contingente mais expressivo.

A psicologia brasileira lava as suas mãos e torna invisível o sofrimento psíquico e social produzido pelo racismo. Como cega, fecha os olhos diante da complexa problemática da formação da identidade dos brasileiros negros e brancos. Pois o racismo e o sofrimento decorrente dele não é uma questão somente para os afro descendentes. O racismo é uma patologia grave nas formas de sociabilidades das pessoas que o produzem e que naturalizam suas expressões de inferioridade e sentimentos de superioridade. O racismo produz o adoecimento psíquico de toda a coletividade, e enquanto epidemiologia em saúde mental e agravos a saúde da população brasileira este é um assunto inerente ao estudo e formação do profissional da saúde psíquica que é o psicólogo (Oliveira, 2016 a).

Sob tal perspectiva a psicologia parece ser produto da branquitude - o privilégio de ser branco - pois forma, através de seu currículo oficial, profissionais incapazes de considerar a população negra existente em maioria no território nacional e organizar praticas psicológicas que combatam e previnam atitudes e pensamentos racistas como modo de promover a elevação da saúde mental de uma população para o desenvolvimento da civilização humana.

Em suma, ainda é preciso muito fazer para que a ciência psicológica reconheça e dediquese as demandas do sofrimento psíquico da população negra, a qual é comumente massacrada e marginalizada por profissionais da saúde física e mental em seus diferentes contextos. A psicologia, campo da subjetividade e das configurações afetivas, mentais e emocionais, precisa ser capaz de promover um olhar sensivel para o papel desempenhado pela branquitude que merece ser problematizado com o objetivo de despertar atitudes mais conscientes nos que se beneficiam dos postos de poder e privilégios simbólicos que geram e mantém o racismo e são a marca da inauguração da ciência psicológica. Enquanto ciência que se desenvolve, a psicologia, no interior formal de seu currículo nas universidades, deve ser capaz de crescer e buscar novos enredos de atuação e transformação de si mesma, das pessoas - negras e brancas - e da sociedade brasileira e mundial. 


\section{REFERÊNCIAS}

ANTUNES, Mitsuko Aparecida Makino. A psicologia no Brasil: leitura histórica sobre sua constituição. São Paulo: Educ, 1998, 5ạ. Ed. 2007.

BRAGA, Ana Paula Mussatti. Pelas Trilhas de Virginia Bicudo : psicanalise e relaçoes raciais em Sao Paulo. Revista Lacuna - uma revista de psicanalise, 06/12/2016, numero 02, ISSN - 2447-2663.

CARONE, Iray e BENTO, Maria Aparecida da Silva (org.). Psicologia social do racismo: estudos sobre branquitude e branqueamento no Brasil. Rio de Janeiro: Editora Vozes, 2002.

CONSORTE, Josildeth Gomes. A questão do negro: velhos e novos desafios. In: São Paulo em Perspectiva, Revista da Fundaçao SEADE, n. 5, janeiro/março, 1991.

COSTA, J.F. Da cor ao corpo a violência do racismo. In: Violência e Psicanalise. Rio de Janeiro: Graal, 1996.

FANON, Frantz. Peau noire, masques blancs. Editions du seuil, Paris, 1952, p.5-6.

MACEY, David. Frantz Fanon : une vie. La Découverte, Paris, 2013.

MUNANGA, Kabenguele. Entrevista concedida a Antonio da Costa Ciampa. Revista ABRAPSO, Psicologia e Sociedade; 12 (1/2):5-17;jan./dez.2000, p.05.

PPP - PROJETO POLITICO PEDAGOGICO. Curso de Psicologia da Universidade Federal do Recôncavo da Bahia , Pro-Reitoria de Graduaçao. Coordenadoria de ensino e integração acadêmica /Nucleo didático pedagógico, 2007.

PPP - PROJETO POLITICO PEDAGOGICO. Curso de Psicologia da Universidade Federal do Recôncavo da Bahia, Pro-Reitoria de Graduaçao. Coordenadoria de ensino e integração acadêmica /NDE - Nucleo Docente Estruturante, 2015.

SOUSA, Neusa santos. Tornar-se negro: as vicissitudes da identidade do negro brasileiro em ascensão social. Rio de Janeiro: Edições Graal, 1983. Coleção Tendências; v.4.

SOUZA OLIVEIRA, Regina Marques de. Sobre crianças no espaço hibrido da esperança: reflexões da psicanalise e da psicologia social. Dissertaçao de Mestrado em Psicologia Social. PUC/SP, 2003.

. Identidade de jovens negros nas periferias das metrópoles: recortes entre São Paulo e Paris. Tese de Doutorado em Psicologia Social. PUC/SP e EHESS/Paris, 2008. 
. Violência e território: saúde mental da população negra no Brasil e da diáspora africana. Projeto de pesquisa pos-doutoral internacional financiada pela CAPES no Instituto dos Mundos Africanos em Paris, sob colaboração cientifica de Elikia M’Bokolo, 2016.

- Cenarios da saúde da população negra no Brasil: diálogos e pesquisas.

Editora Fino Traço/EDUFRB, 1.a ed. 2016.

Regina Marques de Souza Oliveira: Doutora em Psicologia Social, Psicanalista. Pós-doutorado (financiamento CAPES, 2016) no Instituto dos Mundos Africanos em Paris (IMAF/EHESSParis/França) em Saude Mental da Populaçao Negra e Diaspora Africana. Docente da Universidade Federal do Recôncavo da Bahia no Centro de Ciências da Saude e Universidade Estadual do Sudoeste da Bahia (Mestrado em Relaçoes Etnicas e Contemporaneidade/Jequié).

Joice Naiane Santos Lima: Bacharel em Saude. Pesquisadora do NEPPINS - Nucleo de Estudos e Pesquisa em Psicanalise, Identidade, Negritude e Sociedade da Universidade Federal do Recôncavo da Bahia. Graduanda em psicologia na UFRB/Centro de Ciências da Saude/Santo Antonio de Jesus-BA.

Artigo recebido para publicação em: Setembro de 2017.

Artigo aprovado para publicação em: Novembro de 2017. 